chemical and X-ray methods, physical metallurgy investigations, fundamental research by microcinematography on the mechanism of fracture, and various applied investigations; further grants of $2,795,000$ francs and 5,050,000 francs were for continuation of research on the mechanical properties of steel and on methods of utilization of steel, and one of $6,500,000$ francs for continuation of research on cobalt.

The Committee for the Study of the Problem of Nitrogen received a grant of $6,660,000$ francs for research on nitrogenous fertilizers in Belgium soils, including investigations on nitrification and absorption of nitrogen by vegetables. A grant of $6,027,000$ francs to the Centre for Biological Chemistry and Soil Colloids was for investigations on the transformation of organic matter in the soil, mineral colloids of the soil and on the cationic and organic manuring of soils. The Centre for Research into Forestry Biology received 5,590,000 francs for pedological, entomological and genetic research devoted towards improving the exploitation of forests and their conservation by natural regeneration. The Centre for Scientific and Technical Research on the Conservation of Vegetables received a grant of 5,222,000 francs for scientific and technical research on the cultivation of vegetables for conserving and on the conditions of conservation; $4,165,000$ francs went to the Centre for Research on Agriculture for work on the mineral alimentation of vegetables, 3,700,000 francs to the Centre for Research on Vegetable Hormones, 3,210,000 francs to the Centre for Research on Parasitic Diseases of Domestic Animals, 2,835,000 francs to the Centre for the Study of the Forest Soils of Ardennes and Gaume; 5,470,000 francs to the Scientific and Technical Research Centre of the Explosives Industry and 5,174,079 franes to that of the Belgian Textiles Industry. Other grants included $3,350,000$ franes to Dr. C. Janssen's Research Laboratory for research on the synthesis of ring systems with 3 or 4 atoms of carbon; 2,456,450 francs to the Laboratory of the Varnish, Paints, Printing Inks and Art Colours Industry and 2,835,000 franes to the Centre for the Study of Ornamental Plants for work on plant diseases and the cultivation of chrysanthemums and cyclamens. Other grants included 2,162,000 francs to the Technical and Scientific Centre of the Woodworking and Related Industries; $1,980,000$ francs to the Pedological Service of Belgium for researches on magnesium and on minor elements in vegetables; $1,840,000$ francs to the Foundation for Potato Research; 1,770,000 francs to the Committee for the Study of Apiculture; $1,525,000$ francs to the Committee for Strawberry Research; 1,160,000 francs to the Committee for the Scientific and Technical Study of Lactation; and $1,086,000$ franes to the Belgian Institute for High Pressures.

\title{
THE AUSTRALIAN DEFENCE STANDARDS LABORATORIES
}

T

HE function of the Australian Defence Standards Laboratories is outlined in the annual report for the year ended June 30, 1961*. Its main concern is the application of scientific knowledge and research within the fields of chemistry, physics, metallurgy and engineering to problems arising in the design, manufacture, inspection and use of defence material. In addition, as its name implies, it is concerned with standards of measurement and standards of quality. The report deals with the general activities of the establishment and with some of the more important projects and investigations either completed or in progress in the fields of chemistry, metallurgy and physics.

In the Chemistry Division research has continued on the mechanism of the initial film formation on lead alloy anodes in sea-water, and the initial film has been shown to contain lead sulphate and some carbonate, in addition to lead chloride. Infra-red spectroscopy has been used for the study of a series of bis-pyridinium oximes. The cæsium bromide prism of the double pass spectrometer was calibrated for the far infra-red and a curve fitted to twenty points by orthogonal polynomial methods. The best fit was given by a cubic expression. The application of the Stokes parameters of electromagnetic radiation to the description of the state of polariza tion of Raman lines has been considered, and a procedure has been developed for the calculation of the intensity ratios and depolarization factors. The new apparatus of Lench and Martin for lowpressure gas analysis, used in conjunction with improved apparatus for vacuum fusion gas extraction, collection and measurement, has been in constant use during the period under review for the determina-

* Commonwealth of Australia: Department of Supply. Australian Defence Scientific Service. Annual Report of Defence Standards Laboratories for the year ended 30th June, 1961. Pp.
byrnong, Victoria: Defence Standards Laboratories, 1962.) tion of the gas content of chromium metal and chromium alloys by the vacuum fusion method.

During the year, major improvements were made to the control system of the air-conducting plant of the metrology laboratory in the Physics Division to enable temperatures in the Length Standards Room to be maintained at $20^{\circ} \mathrm{C} \pm 1_{4}^{\circ} \mathrm{C}$ irrespective of external conditions. Considerable developments in the application of interferometry to measurements of length are reported. A Varian wide-line nuclear magnetic resonance spectrometer with associated electromagnet and power supply has been installed, and is being used to investigate the concentration of the fluoride catalyst in the chromic acid solutions used in the production of chromium. Electron spin resonance has been used to study the defects produced by $\gamma$-rays on a commercial polymethyl methacrylate. New values for $X$ - and $\gamma$-radiation absorption coefficients have been obtained, and designs for counters for the detection of soft X-rays have been developed and constructed.

The Metallurgy Division has been largely concerned with the evaluation of one of the Australian chromiumbased high-temperature alloys processed under quasiindustrial conditions. This includes ductility studies, internal friction measurements and observations of the creep behaviour. Work has continued on cleavage in cast molybdenum of high purity and in wrought chromium. As a contribution to the understanding of the abrasion of metals, the sliding of a metal specimen on silicon carbide abrasive papers has been studied, and it has been found that the majority of abrasive particles make a groove in the surface of the metal, piling up a ridge on either side, but removing little or no metal. An idealized model of the process has been devised and an expression obtained for the rate of removal of material with allowance made for the deterioration in use of the 
abrasive paper. Using metallographic techniques it has been established conclusively that the damage, produced in the surface layers of slices of germanium for use in semiconductor devices when cut from large single crystals and lapped to size, is due to cracks, and new methods of preparation of the slices which will considerably reduce the extent of the damage are being developed.
The annual report lists the various personnel of the Laboratories and their status, and gives details of the publications by members of the staff during the year under review. The staff numbered 687 on June 30, 1961. Open days were held at Maribyrnong during April 1961, and during the four days some 4,000 persons visited the Laboratories.

S. WeINTROUB

\title{
MENTAL HEALTH IN THE WORLD
}

$T$ is difficult to estimate the prevalence of mental illness, but in countries where services for the mentally ill are relatively highly developed, psychiatric cases account for almost half the total number of patients occupying hospital beds. Apart from cases in hospital, too, a considerable proportion of the world's population suffers from minor forms of mental ill-health which do not require hospitalization but may disorganize social relationships and productive capacity. It has been suggested that to provido satisfactory treatment for all cases of psychiatric disorder one psychiatrist is needed for every 20,000 people-a requirement that has so far been met in only a few areas.

The main concern of the World Health Organization in mental health has been to develop knowledge that can be applied in public health administration by its Member States. The reports of its Expert Committee on Mental Health and of its study groups on related subjects, for example, provide a conspectus of international views on policy in this field as they have developed over the past twelve years. Laying special emphasis on preventive work, the Organization has assisted the development of psychiatric services in Member States through seminars, conferences and fellowships and by providing consultants and expert advice. Its educational influence in mental health has been further extended by its publication of a number of authoritative studieson topics from the architecture of psychiatric hospitals to the epidemiology of mental disorders-by leading international authorities. The World Health Organization has also done much to foster both basic and applied psychiatric research.

A new booklet, which is a reprint of a series of articles that appeared in the WHO Chronicle between March and July 1962, surveys those aspects of mental health work with which the World Health Organization has been particularly concerned *. These include: the development of psychiatric services; the mental health tasks of the public health services; problems of prevention and treatment; education, training and research, and programme development. There is also a bibliography of World Health Organization reports and studies on mental health.

* World Health Organization. WHO and Mental Health, 1949-1961. Pp. 48. (Geneva : World Health Organization; London: H.M. Stationery Office, 1962.) I Swiss frane; $18.9 d . ; 0.30$ dollar.

\section{WIDESPREAD IONOSPHERIC DISTURBANCES DUE TO NUCLEAR EXPLOSIONS DURING OCTOBER 1961}

\author{
By Prof. TATSUZO OBAYASHI
}

\author{
lonosphere Research Laboratory, Kyoto University, Kyoto
}

A SERIES of Soviet nuclear tests made during October 1961 at Novaya Zemlya reveals the evidence of strong blast waves propagating through the ionosphere over a considerable distance. Two large nuclear tests were carried out at $08 \mathrm{~h} 28 \mathrm{~m}$ on 23 and at $08 \mathrm{~h} 33 \mathrm{~m}$ on October 30,1961 , which were probably of 30 and of 50 megatons, respectively. Although the exact situation of the tests at Novaya Zemlya is not known, the detonations were made probably in the troposphere. Some preliminary investigations on the remarkable ionospheric disturbances associated with these explosions have already been reported. At Scandinavian stations, the ionograms showed a sudden heavy disturbance in the $F$ region of the ionosphere about half an hour after the detonation ${ }^{1,2}$. A large increase of $f_{0} F_{2}$ and subsequent oscillatory variations with a period of $1 \frac{1}{2} h$ were found at Lindau, Germany, being delayed about $2 h^{3}$. Short-wave radio communications between Europe and Japan $(G B J-34,14 \cdot 80 \mathrm{Mc} / \mathrm{s}$, and $D G P-862$, $15.86 \mathrm{Mc} / \mathrm{s}$ ) deteriorated immediately and rather poor conditions lasted several hours ${ }^{4}$.

Similar ionospheric disturbances have been known at the high-altitude nuclear explosions over Johnston
Island during August 1958. The travelling $F_{2}$ disturbance was found which spread several thousand kilometres over the Pacific area ${ }^{5-7}$. Photographs of the explosion taken from Hawaii indicated clearly the existence of an expanding luminous front through the upper atmosphere ${ }^{8}$. Since these disturbances may possibly be due to shock waves spreading out from the explosion, the investigation of the present effect by the world-wide ionosonde network would be of great value. Thus, ionospheric data at about 30 stations in the northern hemisphere have been analysed.

The results for two events on October 23 and 30 , the time variations of $f_{0} F_{2}$ at several key stations in Europe and in Asia, and the field-strength record at the route Hamburg-Osaka $(15.86 \mathrm{Mc} / \mathrm{s})$ are illustrated in Fig. 1. The great-circle path of the HamburgOsaka is deviated about $1,000 \mathrm{~km}$ from the shot point. It is shown that an anomalously large increase and subsequent fluctuations of $f_{0} F_{2}$ were observed at all European stations, and smaller effects in Japan. The peak of increased $f_{0} F_{2}$ was delayed progressively from nearer to distant stations. This travelling disturbance was confirmed in India and in South-East Asia. Both 